\title{
Low-carbon development strategy of Russia considering the impact on the economy
}

\author{
Andrey Kolpakov ${ }^{1 *}$ \\ ${ }^{1}$ Institute of Economic Forecasting of the Russian Academy of Sciences (IEF RAS), 47 Nakhimovsky Prospect, Moscow, Russia
}

\begin{abstract}
The article considers the impact of national climate policy on the development of the Russian economy and energy sector. Implementation of an aggressive scenario (which is aimed at containing at any cost the rise in global temperature within $1.5{ }^{\circ} \mathrm{C}$ compared to the pre-industrial era) is unacceptable to Russia from socioeconomic perspective given it leads to lowering the average annual GDP growth rate by 1.8 percentage points by 2050 . Effective long-term development strategy with low GHG emissions level should focus on structural and technological modernization of the economy; improve the absorption potential of the LULUCF sector; stimulate only those structural changes in the energy sector that involve production and technological chains within the country and do not provide for excessive price growth. Russia retains a significant potential for energy efficiency growth, and the necessary condition for activating this process is sustainable economic growth as it involves modernization of the production facilities and using available and competitive industrial capacities. The implementation of a reasonable scenario, based on these principles, would allow Russia to fulfil the nationally determined contributions within the Paris Agreement while ensuring economic growth at the rate not less than the global average one.
\end{abstract}

\section{Overview}

The climate agenda and the goal of transferring the world economy on a development trajectory characterized by low greenhouse gas (GHG) emissions is one of the priority areas in the modern world politics. The Paris Agreement adopted in December 2015 is a document declaring the aspiration of the international community to limit the anthropogenic impact on the planet's climate. The goal of the Paris Agreement is to preserve the increase in average global temperature by the end of the 21 st century within $2{ }^{\circ} \mathrm{C}$ relative to preindustrial indicators, and also to make every possible effort to weak the climate warming even more and stay within $1.5^{\circ} \mathrm{C}$.

Russia signed the Paris Agreement in 2016, stating as a nationally determined contribution (NDC) the goal of restraining net GHG emissions $25-30 \%$ below the 1990 level, and ratified it in 2019.

In 2017, net GHG emissions in Russia (taking into account the LULUCF sector - Land use, land use change and forestry) amounted to $1578 \mathrm{mln} \mathrm{tCO}_{2}$-eq., being at $51 \%$ of the 1990 level. On the one hand, the country has a certain "margin of safety" in terms of a potential increase in emissions. On the other hand, there are several arguments that force us to take the topic of limiting emissions seriously.

First, over the past decade, the average annual GDP growth rate in Russia did not exceed $1 \%$. The current situation is perceived as unacceptable by both the political and the expert community. A sound consequence was the President's May decree, the key goals of which are related to accelerating the national economic dynamics (to the level not lower than the world average one), the growth of the population's real income, the fight against poverty. The problem is that the reaching of these goals with the existing production and technological structure of the Russian economy may cross the "Paris" limit on GHG emissions already in 2030-2035. [1]

Second, in the retrospective period, the most important driver for reducing net GHG emissions in the country was the carbon absorption by Russian forests. During 1990-2010 the absorption of GHG emissions by forests has grown 3 times from 225 to $749 \mathrm{mln} \mathrm{tCO}_{2}$-eq. However, a turning point occurred then, and by 2017 this indicator decreased by $13 \%$ to $655 \mathrm{mln} \mathrm{tCO}_{2}$-eq. There are risks of a further serious decrease in the absorbing capacity of Russian forests. Given the current scale of logging and the level of fire protection, as well as taking into account the increase in forest age, the level of annual carbon accumulation in Russian forests will halve by the mid-2030s [2].

Third, the Paris Agreement involves the principle of increasing ambition, which means a gradual lowering the GHG limiting cap. Therefore, after 2030, Russia's goal to curb net GHG emissions may well be $65-70 \%$ or even $60-65 \%$ of the 1990 level, which will seriously aggravate the GHG emission regulation agenda.

The largest source of GHG emissions is the combustion of carbon-containing fossil fuels to meet energy demand, with the accompanying production of $\mathrm{CO}_{2}$. Energy

\footnotetext{
* Corresponding author: ankolp@gmail.com
} 
related $\mathrm{CO}_{2}$ emissions accounted for two thirds of all GHG emissions in Russia (excluding LULUCF). Table 1 shows the drivers of forming the energy related $\mathrm{CO}_{2}$ emissions.

Table 1. Drivers of energy related $\mathrm{CO}_{2}$ emissions in Russia and worldwide $(1990=100)$.

\begin{tabular}{|c|c|c|c|}
\hline & 1990 & 2000 & 2017 \\
\hline \multicolumn{4}{|l|}{ Russia } \\
\hline Energy related $\mathrm{CO}_{2}$ emissions & 100 & 68 & 71 \\
\hline Population & 100 & 99 & 97 \\
\hline GDP per capita & 100 & 68 & 122 \\
\hline Energy intensity of GDP & 100 & 105 & 70 \\
\hline Carbon intensity of energy & 100 & 97 & 85 \\
\hline \multicolumn{4}{|l|}{ World } \\
\hline Energy related $\mathrm{CO}_{2}$ emissions & 100 & 113 & 160 \\
\hline Population & 100 & 116 & 142 \\
\hline GDP per capita & 100 & 116 & 173 \\
\hline Energy intensity of GDP & 100 & 85 & 65 \\
\hline Carbon intensity of energy & 100 & 99 & 100 \\
\hline
\end{tabular}

Source: IEA

In 1990-2017, energy related $\mathrm{CO}_{2}$ emissions in Russia decreased by $29 \%$. The main increasing driver for them was the economic dynamics - GDP per capita grew by $22 \%$ with a slight decline in the population (by $3 \%$ ). And the key restraining factor was the $30 \%$ decline in the energy intensity of GDP. The carbon intensity of consumed energy (which depends on the structure of the various energy resources use) also contributed (but less than the energy efficiency parameters), decreasing by $15 \%$.

In fact, the main restraining factor globally is also the energy efficiency improvement. In 1990-2017, energy related $\mathrm{CO}_{2}$ emissions in the world increased by $60 \%$. The main drivers of the increase in emissions were the growth of the population (by 42\%) and GDP per capita (by $73 \%$ ). The main limiting factor for $\mathrm{CO}_{2}$ emissions was the reduction in the energy intensity of the world GDP by $35 \%$. At the same time, the carbon intensity of consumed energy on the global scale has changed little over the past almost 30 years (and it has not decreased but increased by $0.4 \%$ ). This is the reason why the lowcarbon strategies developed and adopted in different countries, while continuing to rely heavily on the energy efficiency, are trying at the same time to activate the "structural" factor, promoting ideas for a complete transition to the energy system based on renewables, electrification (including transport) and hydrogen technologies.

Russia has significant potential to reduce the carbon intensity of its economy. The list of principal directions includes maximizing the absorption capacity of natural ecosystems, increasing energy efficiency in all areas of the economy, and structural transformation of industries towards reducing the GHG emissions. Moreover, many particular measures can be distinguished in each direction (use of the best available technologies; increasing the degree of processing the raw materials; forest planting; elimination of GHG leaks on the energy infrastructure; spread of renewables and smart grids in the electric power industry, electric furnace - in metallurgy, electric vehicles - in transportation; electric stoves - in the residential sector, modern systems of municipal waste management - in communal services, soil-saving technologies - in agriculture, etc.). The only question is which of the existing measures are effective in the Russian conditions and which are not.

\section{Methods}

In order to analyze the economic efficiency of different measures of decarbonizing the Russian economy, we used a system of macrostructural models developed at the IEF RAS. It includes the interindustry model of the Russian economy [3-4], supplemented by the calculated energy balance and the unit of net GHG emissions (Fig. 1).

Measures to reduce the GHG emissions are the exogenous factor that allows the transition between different scenarios. They affect most macroeconomic indicators through the dynamics of capital expenditures and restrictions/incentives on the output of particular products. Thus, the dynamics of production by type of economic activity is formed, which, among other things, is influenced by technological changes associated with shifts in the cost structure. Structural shifts in the economy, along with the parameters of the development of the external market and the structural characteristics of electricity generation, determine the indicators of the energy balance, which, as a factors for the output of the energy sector, return to the interindustry model providing the looped calculation structure.

The unit of GHG emissions is based on the results of the interindustry maroeconomic model (for non-energy emissions) and the energy balance (for energy related emissions). Another element of the emissions unit includes GHG removals in the LULUCF sector, which is mostly exogenous and based on the existing forecast for the carbon balance of Russian forests, but also involves the measures to increase their absorption potential.

Such approach allows to reconcile the dynamic and structural (sectoral) characteristics of the economy in the chosen scenario, as well as to take into account the specific issues of energy sector development in order to obtain the basis for calculating net GHG emissions.

\section{Scenarios}

The Baseline Scenario assumes the achievement of the goal to reach the Russian GDP growth rate not lower than the world average one as well as the targets of national development strategies in different areas. This scenario is based on the realization of the resource potential of Russia for the formation of incomes, which are used to achieve the adopted targets and provide the limited technological modernization of the economy (by financing technological imports). 


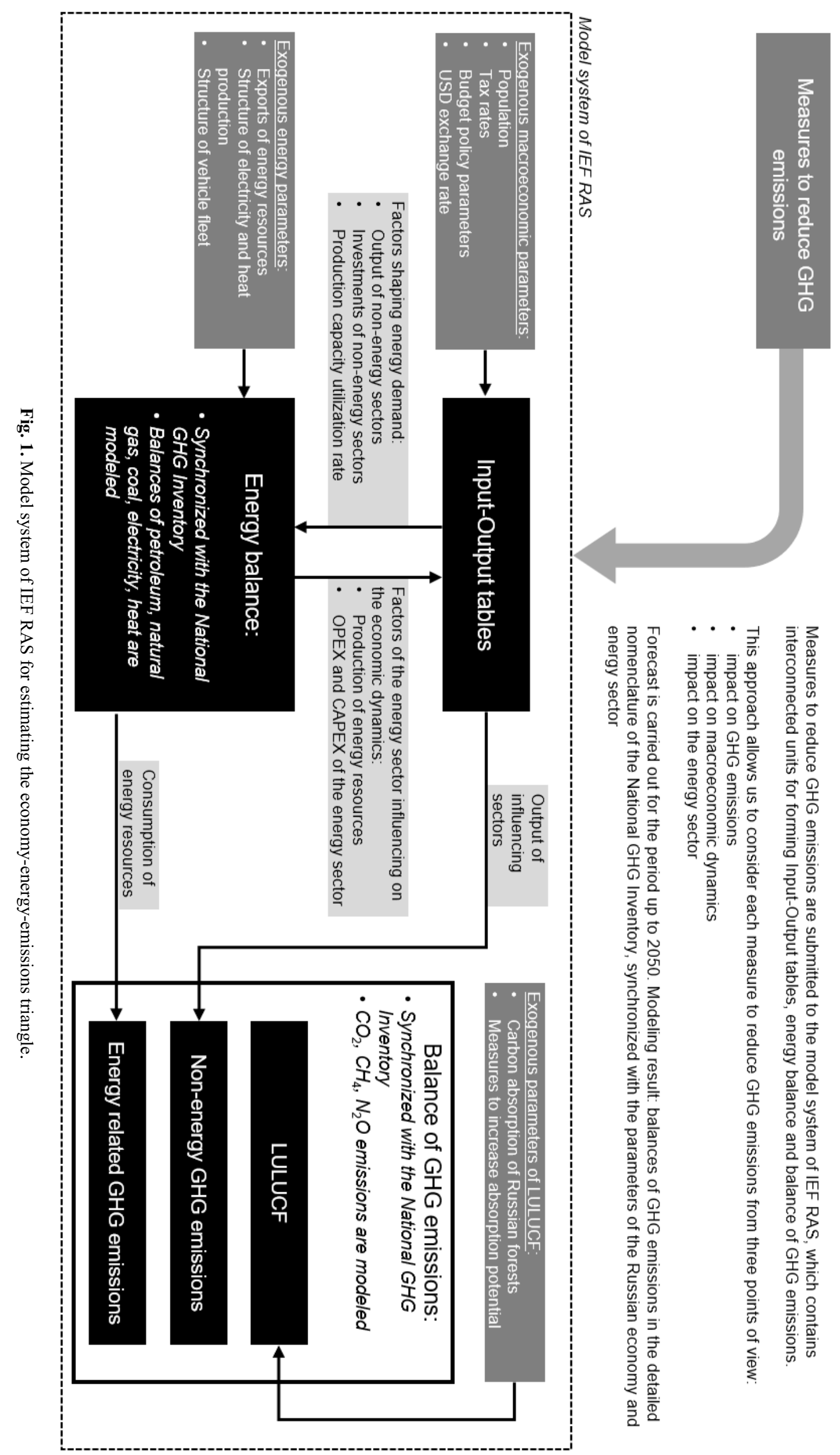


The key risk of the Baseline Scenario is that, without eliminating Russia's technological lag, net GHG emissions may reach the critical values (not allowing to fulfill Russia's NDC under the Paris Agreement) already by $2030-2035$. In this regard, there is a task to build the scenarios of Russia's development which are in line with its existing climatic ambitions. This alternative includes two principle options.

The Reasonable Scenario is based on compliance with the Paris Agreement (taking into account the increase in the ambitiousness of the stated goals after 2030 to 60 $65 \%$ of the 1990 level by 2050) mainly due to the internal potential of the Russian economy. In this scenario, the ultimate goal is to improve the quality and standard of living of people on the basis of structural and technological modernization of the Russian economy (which strongly relies on the income from the exports of energy resources and raw materials until 2030). A comprehensive increase in efficiency not only positively affects the carbon intensity of the Russian economy, but also allows financing of specialized measures to limit GHG emissions.

The Aggressive Scenario targets the reduction of net GHG emissions as the main tool for achieving the ultimate goal - preventing the global temperature from rising by more than $1.5{ }^{\circ} \mathrm{C}$ by the end of the century compared to the pre-industrial era - regardless of the possible consequences for sustainable development of the Russian economy.

Table 2 shows the characteristics of the developed scenarios.

\section{Results}

Fig. 2 shows the dynamics of net GHG emissions in Russia corresponding to each developed scenario; Fig. 3 shows the dynamics and structure of primary energy consumption; Table 3 presents a factor analysis of changes in the net GHG emissions and the average annual growth rate of the Russian GDP in the period up to 2050 .

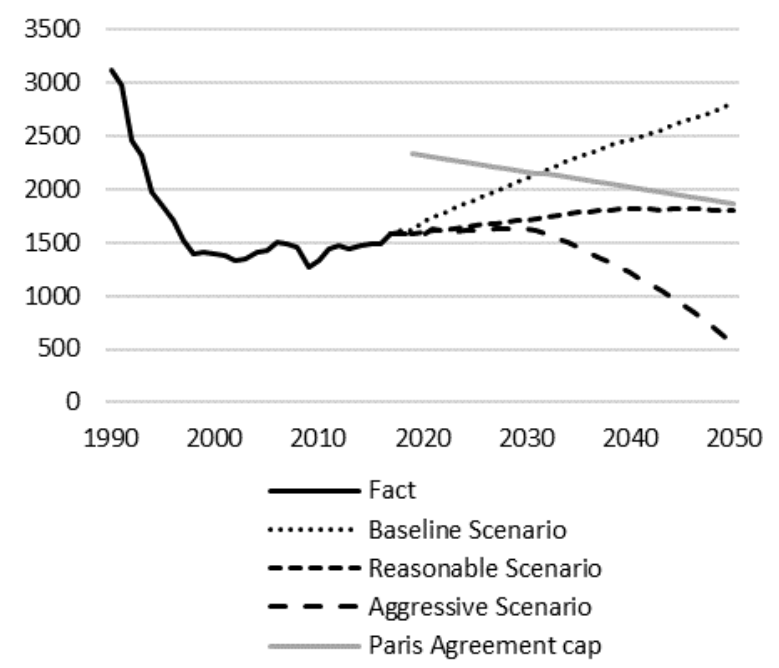

Fig. 2. Net GHG emissions in Russia for developed scenarios, mln $\mathrm{tCO}_{2}$-eq.
The key features of the Reasonable Scenario (compared with the Baseline scenario) are as follows: a) lower total primary energy consumption due to higher energy efficiency given comparable rates of economic dynamics (more on this below); b) the decrease in the share of hydrocarbons in the primary energy consumption balance down to $74 \%$ by 2050 (for comparison, in the Baseline Scenario, their share is $84 \%$ in 2050 , and their actual share in 2017 is $87 \%$ ); c) the expansion of carbonfree forms of energy occurs mainly due to nuclear energy; d) the consumption of liquid and gaseous fuels is growing, but this is largely due to their non-energy use, because diversification of the economy will be associated with a dynamic expansion of chemical production (in 2017 a fifth of all petroleum products were sent for non-energy needs, and by 2050 already half of them can be used for such needs. The same values for natural gas are $10 \%$ and $25 \%$ respectively).

Features of the Aggressive Scenario: a) significantly lower primary energy consumption due to the decline in the economic growth (more on this below); b) the share of carbon-containing energy resources will decrease to $40 \%$ by 2050 , and the expansion of the carbon-free energy resources share is based on renewables, which are massively replacing natural gas and coal in the power sector; c) though electric vehicles will occupy two-thirds of the vehicle fleet, the consumption of liquid fuels until the middle of the century will remain at a comparable level with the current indicators (which happens mostly due to non-road use).

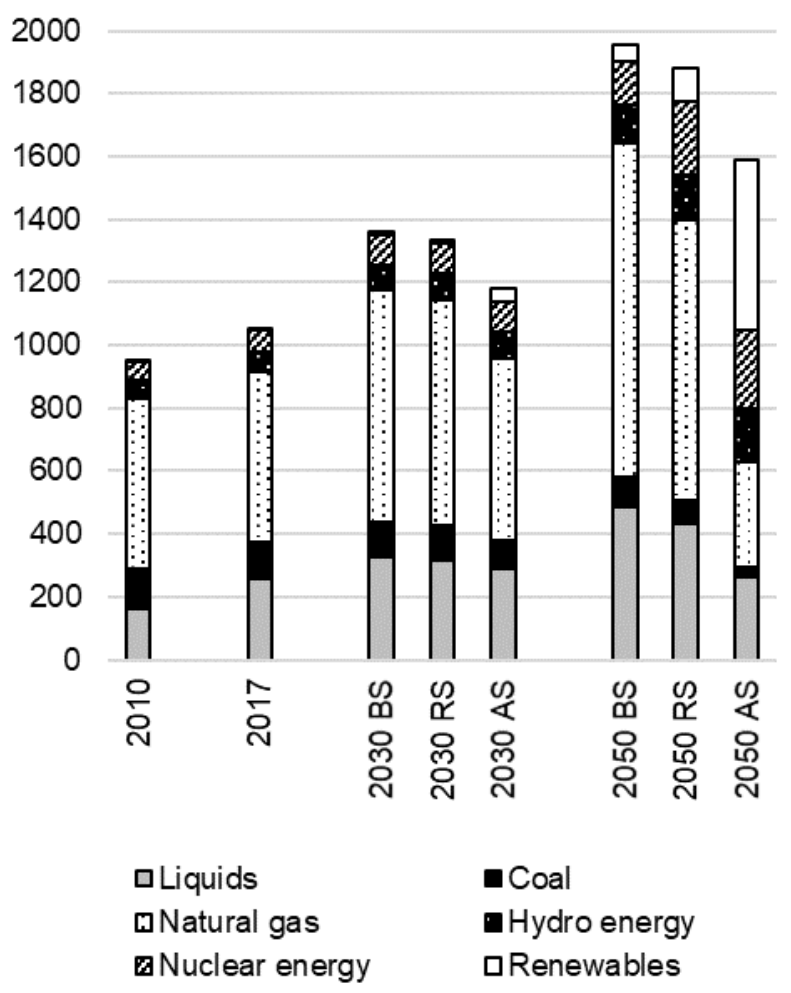

Fig. 3. Primary energy consumption in Russia for developed scenarios, mln tce (BS - Baseline Scenario, RS - Reasonable Scenario, AS - Aggressive Scenario). 


\begin{tabular}{|c|c|c|c|c|c|c|c|c|c|c|c|}
\hline 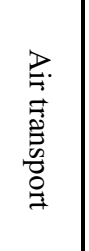 & 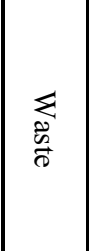 & $\begin{array}{l}\vec{\Xi} \\
\stackrel{\Xi}{\pi} \\
\stackrel{T}{1}\end{array}$ & 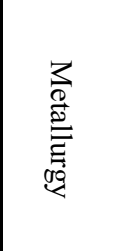 & 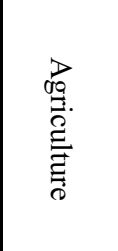 & 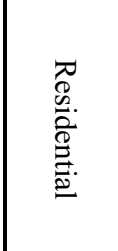 & 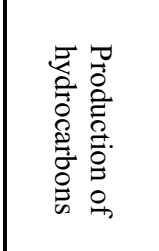 & 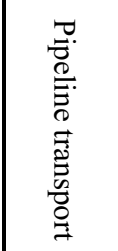 & 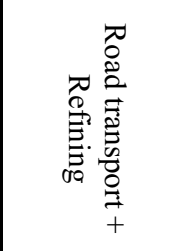 & 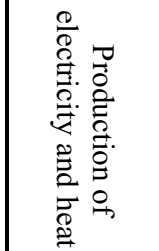 & 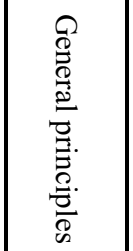 & \\
\hline 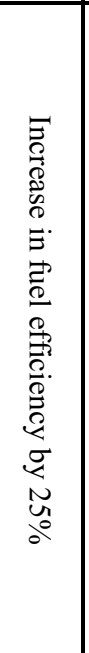 & 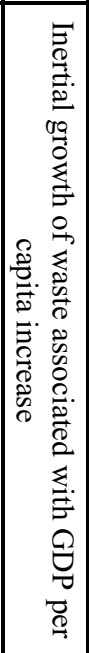 & 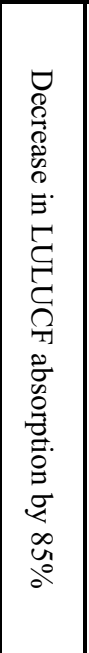 & 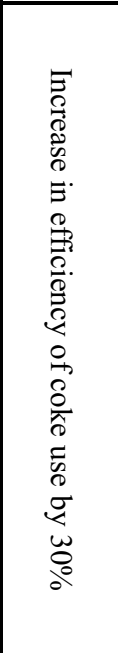 & 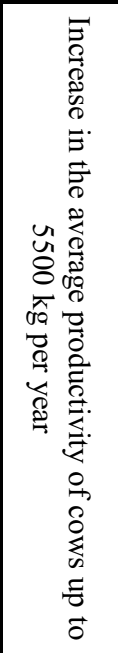 & 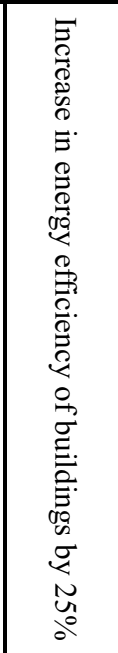 & 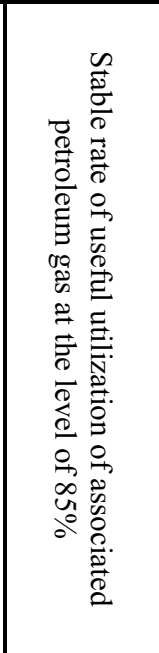 & 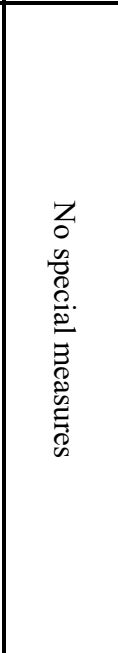 & 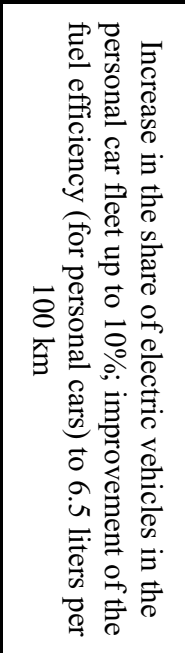 & 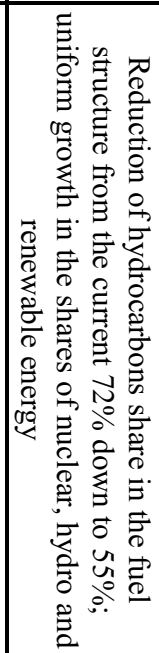 & 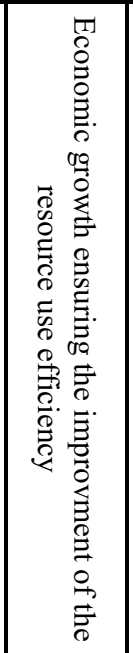 & 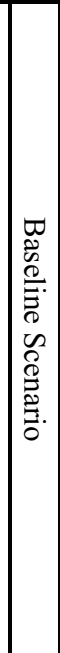 \\
\hline 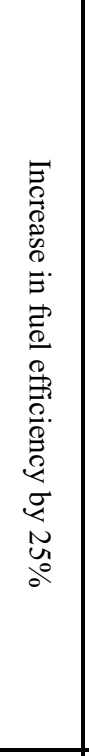 & 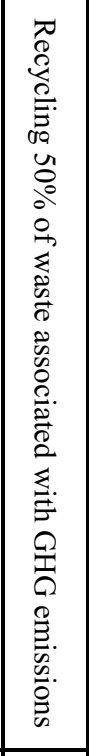 & 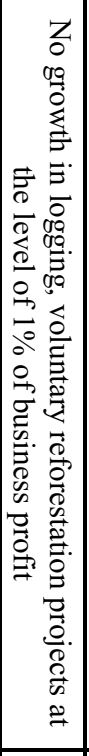 & 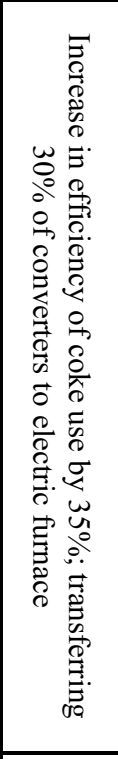 & 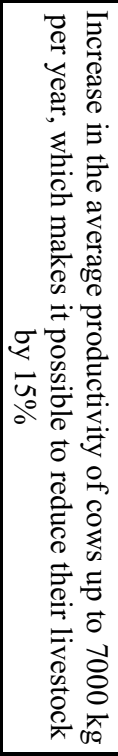 & 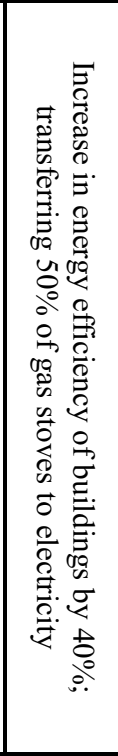 & 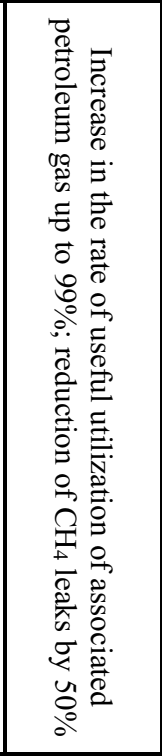 & 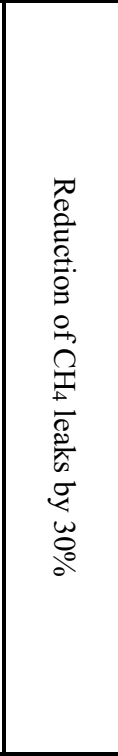 & 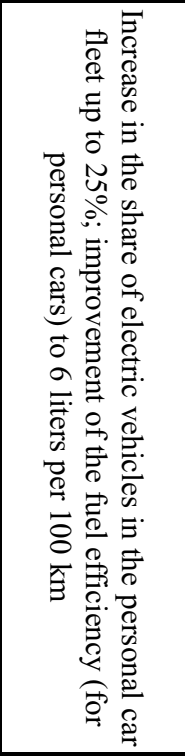 & 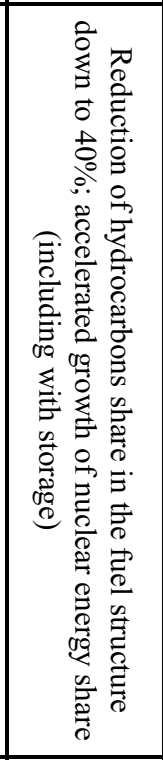 & 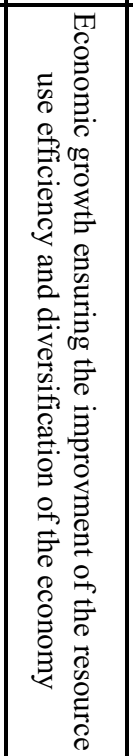 & 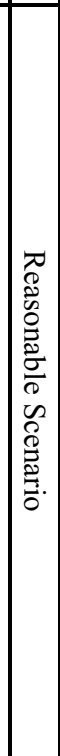 \\
\hline 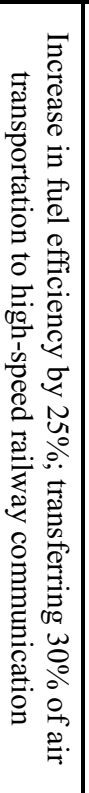 & 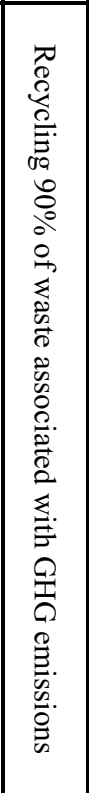 & 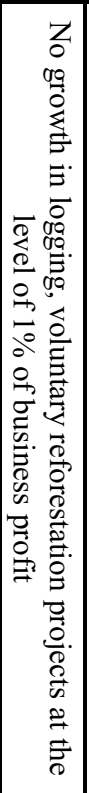 & 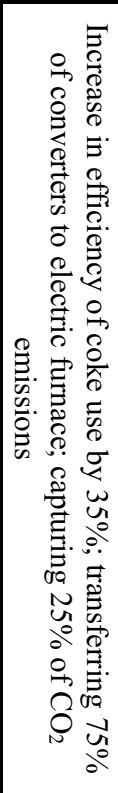 & 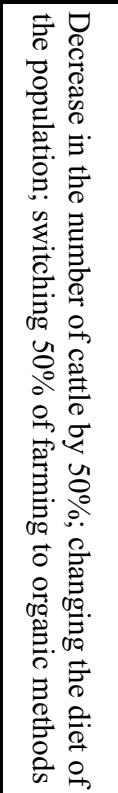 & 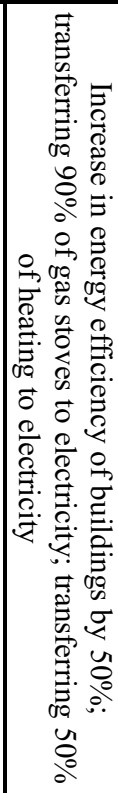 & 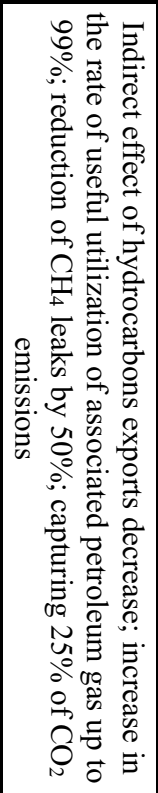 & 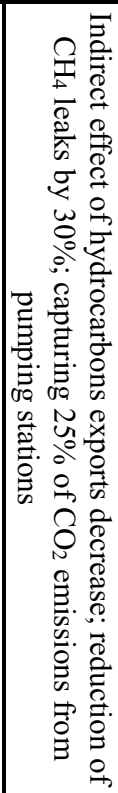 & 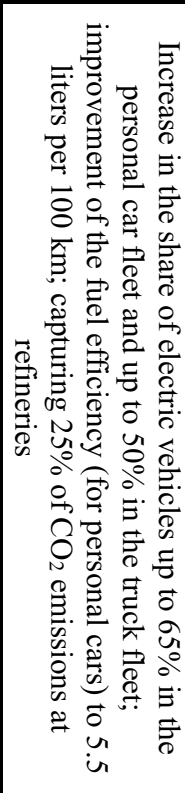 & 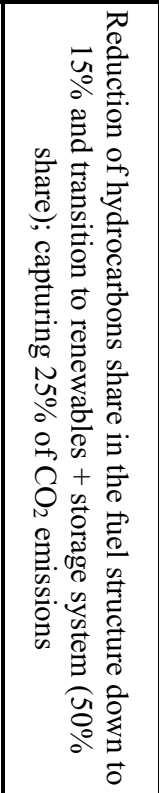 & 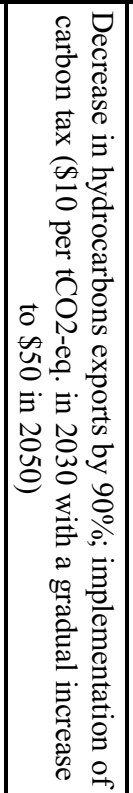 & 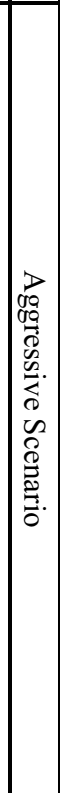 \\
\hline
\end{tabular}




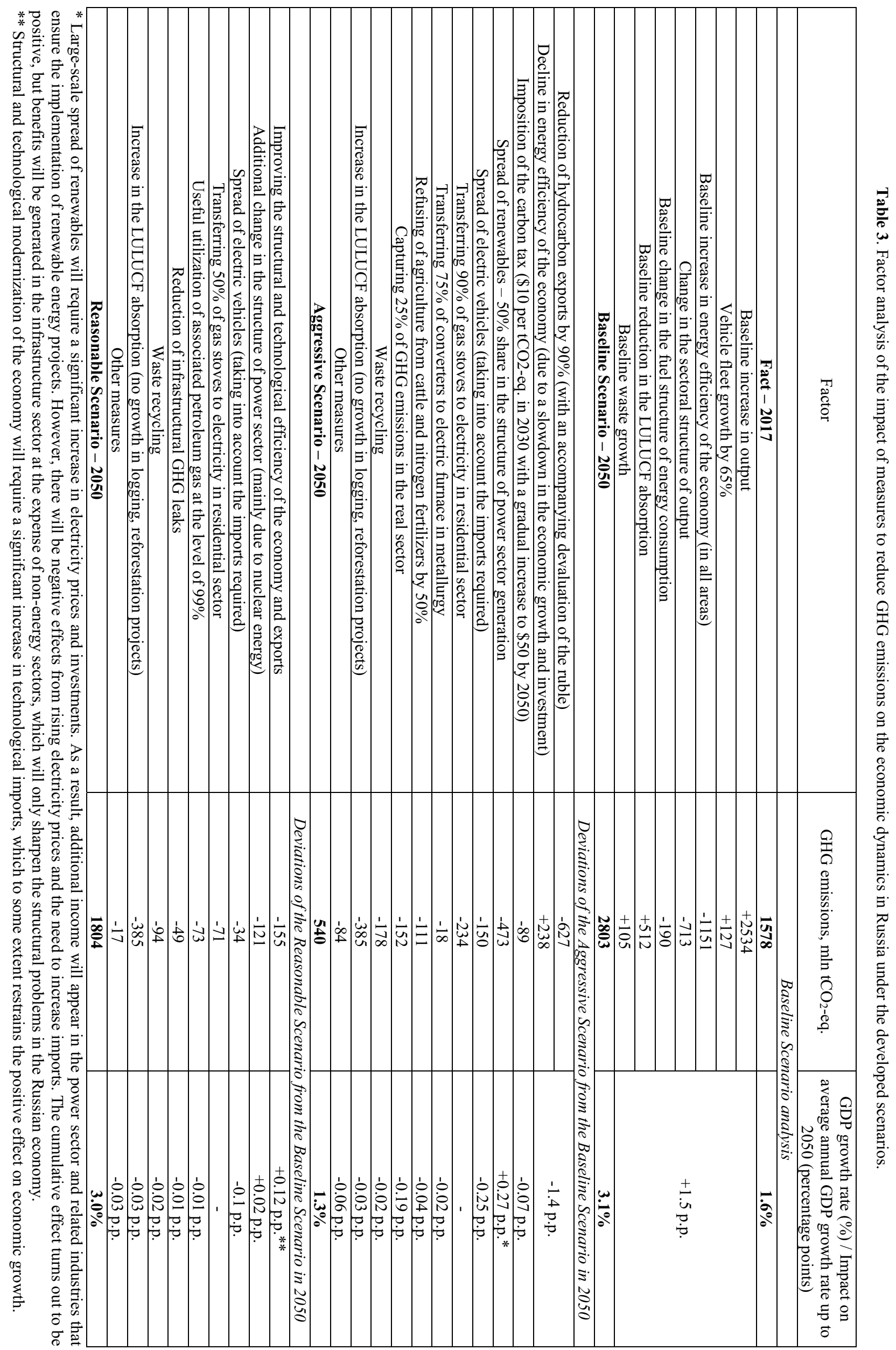


Our estimations show that implementation of the Aggressive Scenario turns out to be incompatible with sustainable economic growth in Russia. The collapse of hydrocarbon sector, the devaluation of the national currency, high mitigation costs that are unproductive from the economic point of view at times, and the import of technologies to reduce emissions are factors that cannot be leveled out. The price of the Aggressive Scenario for the Russian economy is lowering the average annual GDP growth rate by 1.8 percentage points by 2050 . In addition, tough measures to reduce GHG emissions involve energy costs increase to unprecedented levels - from the current $13 \%$ of the GDP to $30 \%$ of the GDP by 2040 . Such a burden would hardly be compatible with economic growth. In any case, with such dynamics, economic growth will not translate into an improvement in the standard of living of the population. An important factor in the degradation of economic dynamics in this scenario is the inability to use the potential of the oil and gas sector in order to finance the modernization of the economy and the inability to fully replace its contribution to the formation of GDP with other sectors.

Following the Reasonable Scenario involves structural and technological modernization of the economy, which leads to an increase in its efficiency. It is the main resource that provides income to finance costs aimed at reducing net GHG emissions (a significant part of which is unproductive and associated with imports). As a result, the loss of the GDP growth rate turns out to be minimal $(-0.1$ percentage points in the period up to 2050).

Thus, with the correct alignment of priorities and the formation of a balanced climate policy, it is possible to achieve compliance with the Paris Agreement with a simultaneous growth of the Russian economy at rate not lower than the world average one.

\section{Conclusions}

Russia needs the long-term development strategy with low GHG emissions level focused on improving the quality of living, modernizing and increasing the competitiveness of the national economy. Such a strategy should rest on the following principles: 1) Russia has been the world leader in the GHG emissions reduction since 1990, so no solid reason exists for its soonest switching to excessively strict climate policy which result in additional restrictions to its socioeconomic development; 2) The core obstacle to sustainable development of Russia is not a high level of the GHG emissions, but economic stagnation. Therefore, in terms of macroeconomic priorities, only such a scenario of restricting emissions is acceptable, which allows the Russian economy to develop with an average annual growth rate of at least $3 \% ; 3$ ) Action priorities in the area of the GHG sinking should involve improvement of the LULUCF sector potential by promoting sound natural resources management policy and voluntary projects to increase carbon absorption capacity of the ecosystems; 4) Action priorities to reduce GHG emissions assume the stimulating only those structural changes in the energy sector that involves production and technological chains within the country and do not lead to an excessive price growth. Such change includes increasing use of natural gas (as the «cleanest» fossil fuel) and nuclear energy (given Russia's leading position in the nuclear technology area), as well as cogeneration of electricity and heat. Pronounced increase in using renewables, energy storage systems and electric vehicles should be acceptable only if production of these is successfully localized and costs are reduced; 5) At the same time, Russia retains a significant potential for energy efficiency growth. A necessary condition for activating this process is sustainable economic growth as it involves modernization of the production facilities and using available and competitive industrial capacities. Specific measures targeted at energy savings will be inefficient given economic stagnation.

This research was funded by Russian Foundation for Basic Research (RFBR) project 18-00-00600 (18-00-00599) "Analysis and Strategies for Managing Climate Risks of LongTerm Socio-Economic Development of Russia".

\section{References}

1. A.A. Shirov, A.Yu. Kolpakov. Russian economy and mechanisms of global climate regulation. Zh. Nov. Ekon. Assots. 4. 87-110 (2016). https://doi.org/10.31737/2221-2264-2016-32-4-4.

2. D.G. Zamolodchikov, V.I. Grabovskii, G.N. Korovin, M.L. Gitarskii, V.G. Blinov, V.V. Dmitriev, W.A. Kurz. Carbon budget of managed forests in the Russian Federation in 1990-2050: Post-evaluation and forecasting. Russ. Meteor. and Hydrol. 38 (10), 701-714 (2013). https://doi.org/10.3103/S1068373913100087.

3. Shirov A.A., Yantovskii A.A. RIM interindustry macroeconomic model: Development of instruments under current economic conditions. Stud. on Russ. Econ. Devel. $28.241-252$ (2017). https://doi.org/10.1134/S1075700717030121.

4. Shirov A.A., Yantovskii A.A. Input-output macroeconomic model as the core of complex forecasting calculations. Stud. on Russ. Econ. Devel. 25., 225-234

(2014). 